\title{
Characterization of the Inhibitory Effect of Vascular Endothelium on Agonist-Induced Vasoconstriction in Rat Mesenteric Resistance Arteries
}

\author{
Xin Jin ${ }^{1}$, Yukiko Satoh-Otonashi ${ }^{1}$, Yoshito Zamami ${ }^{1}$, Toshihiro Koyama ${ }^{1}$, Pengyuan Sun ${ }^{1}$, \\ Yoshihisa Kitamura ${ }^{2}$, and Hiromu Kawasaki ${ }^{1, *}$ \\ ${ }^{I}$ Department of Clinical Pharmaceutical Science, ${ }^{2}$ Department of Pharmaceutical Care and Health Science, \\ Graduate School of Medicine, Dentistry and Pharmaceutical Sciences, Okayama University, \\ 1-1-1 Tsushima-naka, Okayama 700-8530, Japan
}

Received May 9, 2008; Accepted July 22, 2008

\begin{abstract}
Vascular endothelium regulates vascular tone by releasing endothelium-derived vasoactive substances. We performed this study to characterize the inhibitory effect of the endothelium on vasoconstrictor stimuli in rat mesenteric vascular beds. Changes in perfusion pressure induced by continuous perfusion of Krebs solution containing methoxamine $\left(\alpha_{1}\right.$ adrenoceptor agonist) or high $\mathrm{KCl}$ were measured over $180 \mathrm{~min}$. In preparations with intact endothelium, methoxamine-induced vasoconstriction was time-dependently decreased to cause $60 \%-80 \%$ reduction of the initial vasoconstriction level, while no reduction was observed in high-KCl-induced vasoconstriction. Endothelium removal significantly blunted the timedependent reduction of methoxamine-induced vasoconstriction without affecting high- $\mathrm{KCl}-$ induced vasoconstriction. Neither a nitric oxide synthase inhibitor (L-NAME) nor indomethacin (cyclooxygenase inhibitor) altered the time-dependent reduction of vasoconstriction. High $\mathrm{KCl}$, $\mathrm{K}^{+}$-channel inhibitors tetraethylammonium and apamin plus charybdotoxin, and $18 \alpha$-glycyrrhetinic acid (18 $\alpha$-GA, a gap-junction inhibitor) significantly inhibited the time-dependent reduction of methoxamine-induced vasoconstriction. In preconstricted preparations, bolus injection of acetylcholine and $\mathrm{Ca}^{2+}$-ionophore A23187 (A23187) evoked a sharp vasodilation, which was inhibited by endothelium removal, high $\mathrm{KCl}$ and tetraethylammonium, but not indomethacin, LNAME, or $18 \alpha$-GA. However, $18 \alpha$-GA plus L-NAME inhibited vasodilation induced by A23187, but not acetylcholine. These findings suggest that endothelium-derived hyperpolarizing factor (EDHF) via gap junctions mainly counteracts vasoconstriction induced by methoxamine in mesenteric resistance arteries.
\end{abstract}

Keywords: methoxamine-induced vasoconstriction, endothelium-derived hyperpolarizing factor, rat mesenteric resistance artery, gap junction

\section{Introduction}

Vascular smooth muscles in physiological conditions are always exposed to vasoconstrictor stimuli from the outside adventitia via perivascular sympathetic adrenergic nerves, which release the neurotransmitter noradrenaline to produce active tone by activating $\alpha_{1}$ adrenoceptors on smooth muscle cells (1). It is widely accepted that the endothelium at the luminal surface of

*Corresponding author. kawasaki@pheasant.pharm.okayama-u.ac.jp Published online in J-STAGE on September 11, 2008 (in advance) doi: 10.1254 /jphs.08115FP blood vessels is an important regulator of vascular tone via release of various endothelium-derived endogenous substances $(2,3)$. Endothelial cells release endotheliumderived factors such as relaxing factors (EDRF) and contracting factors (EDCF) $(4-6)$. EDCF and EDRF include endothelin, prostaglandin $F_{2 \alpha}$, and thromboxane $\mathrm{A}_{2}$ and include nitric oxide (NO), prostaglandin $\mathrm{I}_{2}\left(\mathrm{PGI}_{2}\right)$, and endothelium-derived hyperpolarizing factor(s) (EDHF), respectively. The removal and dysfunction of the vascular endothelium have been recognized to augment vasoconstriction induced by various stimulus and vasoactive agonists such as adrenergic nerve stimulation, noradrenaline, and serotonin, suggesting that the 
endothelium regulates vasoconstriction by releasing EDRF including $\mathrm{NO}$ and $\mathrm{PGI}_{2}$ in the aorta $(7-9)$. Our recent study demonstrated that the endothelium also regulates vasodilation by releasing EDCF, including vasoconstrictor prostanoids and thromboxane $\mathrm{A}_{2}(10)$.

Evidence has accumulated that $\mathrm{NO}$ and $\mathrm{PGI}_{2}$ of EDRF play a prominent role in the tone control of large conduit arteries, whereas EDHF plays a major role in the distal mesenteric arteries in response to vasoactive substances or physical stimuli such as shear stress and pulsatile stretch (11). Therefore, it has been assumed that in the rat mesenteric circulation, as the vessel size decreases the role of EDHF in the endothelium-dependent relaxation increases, and there is a significant interdependent interaction between $\mathrm{NO}, \mathrm{PGI}_{2}$, and $\operatorname{EDHF}(12,13)$. EDHF, which has been described as an endotheliumderived non-NO and non- $\mathrm{PGI}_{2}$ factor, induces hyperpolarization of vascular smooth muscle by opening $\mathrm{K}^{+}$channels $(5,14,15)$ in response to endothelial agonists such as acetylcholine and bradykinin and various physical stimuli. Additionally, gap junctions between endothelial cells and smooth muscle cells have been shown to be involved in EDHF-mediated relaxation (16). However, the role of EDHF in the modulation of the agonistinduced vasoconstrictor response of vascular smooth muscle in peripheral resistance arteries has not been extensively studied.

Therefore, the present study was designed to investigate the role of the vascular endothelium in the regulation of methoxamine ( $\alpha_{1}$-adrenoceptor agonist)-induced vasoconstriction in rat mesenteric vascular beds. We here show evidence that EDHF via gap junctions mainly counteracts continuous vasoconstriction induced by methoxamine in the mesenteric resistance arteries of the rat.

\section{Materials and Methods}

\section{Animals}

Male Wistar rats weighing 250-280 g (8-week-old) were used in this study. The animals were given food and water ad libitum. They were housed in the Animal Research Center of Okayama University at a controlled ambient temperature of $22^{\circ} \mathrm{C} \pm 2$ with $50 \pm 10 \%$ relative humidity and a 12-h light / 12-h dark cycle (lights on 0800 hours). This study was carried out in accordance with the Guidelines for Animal Experiments at Okayama University Advanced Science Research Center, Japanese Government Animal Protection and Management Law (No. 105), and Japanese Government Notification on Feeding and Safekeeping of Animals (No. 6). Every effort was made to minimize the number of animals used and suffering.

\section{Perfusion of the mesenteric vascular bed}

The animals were anesthetized with pentobarbital-Na $(50 \mathrm{mg} / \mathrm{kg}$, intraperitoneally) and the mesenteric vascular beds were isolated and prepared for perfusion as described previously $(17,18)$. The isolated mesenteric vascular bed was placed in a water-jacketed organ bath maintained at $37^{\circ} \mathrm{C}$ and perfused with a modified Krebs solution at a constant flow rate of $5 \mathrm{ml} / \mathrm{min}$ with a peristaltic pump (model AC-2120; ATTO Co., Tokyo). Preparations were also superfused with the same solution at a rate of $0.5 \mathrm{ml} / \mathrm{min}$ to prevent drying. The Krebs solution was bubbled with a mixture of $95 \% \mathrm{O}_{2}-5 \%$ $\mathrm{CO}_{2}$ before passage through a warming coil maintained at $37^{\circ} \mathrm{C}$. Modified Krebs solution was of the following composition: $119.0 \mathrm{mM} \mathrm{NaCl}, 4.7 \mathrm{mM} \mathrm{KCl}, 2.4 \mathrm{mM}$ $\mathrm{CaCl}_{2}, 1.2 \mathrm{mM} \mathrm{MgSO}$, $25.0 \mathrm{mM} \mathrm{NaHCO}, 1.2 \mathrm{mM}$ $\mathrm{KH}_{2} \mathrm{PO}_{4}, 0.03 \mathrm{mM}$ disodium ethylenediaminetetraacetic acid, and $11.1 \mathrm{mM}$ dextrose ( $\mathrm{pH}$ 7.4). High $\mathrm{KCl}$ solution was prepared by equimolar replacement of $\mathrm{NaCl}$.

Changes in the perfusion pressure were measured with a pressure transducer (model TP-400T; Nihon Kohden, Tokyo) and recorded using a pen recorder (model U-228; Nippon Denshi Kagaku, Tokyo).

\section{Chemical removal of the vascular endothelium}

To remove the vascular endothelium, preparations with resting tone were perfused with $1.80 \mathrm{mg} / \mathrm{ml}$ of sodium deoxycholate in saline for $30 \mathrm{~s}$, as described previously $(19,20)$. This caused a transient increase $(20$ to $30 \mathrm{mmHg}$ ) in perfusion pressure. Then, the preparations were rinsed with sodium deoxycholate-free Krebs solution for $60 \mathrm{~min}$ and subjected to perfusion with various agents. After the preparation was contracted by perfusion with Krebs solution containing methoxamine $(2 \mu \mathrm{M})$, successful removal of the endothelium was assessed by the lack of a relaxant effect to a bolus injection of $1 \mathrm{nmol}$ acetylcholine, which was injected directly into the perfusate proximal to the arterial cannula by an infusion pump (model 975; Harvard Apparatus, S Natick, MA, USA). Volumes were $100 \mu \mathrm{l}$ over $12 \mathrm{~s}$.

\section{Bolus injection of acetylcholine and A23187}

After equilibration for $30 \mathrm{~min}$, the preparation was perfused with Krebs solution containing methoxamine $(2-7 \mu \mathrm{M})$ to induce submaximal contraction. After stabilization of the elevated perfusion pressure, the preparation was subjected to bolus injections of $1 \mathrm{nmol}$ acetylcholine (muscarinic acetylcholine-receptor agonist) and $10 \mu \mathrm{mol}$ A23187 $\left(\mathrm{Ca}^{2+}\right.$-ionophore), which were infused directly into the perfusate proximal to the arterial cannula with an injection pump. Injection volumes were $100 \mu$ l over $12 \mathrm{~s}$. 


\section{Experimental protocols}

After the basal perfusion pressure had stabilized, each preparation with or without the endothelium was perfused with Krebs solution containing methoxamine $(3,7$, or $10 \mu \mathrm{M})$ or high $\mathrm{KCl}$ medium (high $\mathrm{KCl} ; 30,60$, or $80 \mathrm{mM}$ ) to induce an increase in perfusion pressure due to vasoconstriction, and changes in perfusion pressure were observed for over $180 \mathrm{~min}$.

To assess the underlying mechanisms, changes in perfusion pressure induced by methoxamine and high $\mathrm{KCl}$ were observed in the preparation without an endothelium. In the experiment using the endotheliumdenuded preparation, the concentration of methoxamine was reduced to $2 \mu \mathrm{M}$, which induced an increase in perfusion pressure to a level similar to that in preparations with intact endothelium, since endothelium removal enhanced the vasoconstrictor response to methoxamine (10).

In another series of experiments, combined perfusion of $N^{\mathrm{G}}$-L-nitro arginine methyl ether (NO synthase inhibitor; L-NAME, $100 \mu \mathrm{M}$ ), indomethacin (cyclooxygenase inhibitor, $1 \mu \mathrm{M})$, high $\mathrm{KCl}(30 \mathrm{mM})$, tetraethylammonium $\left(\mathrm{Ca}^{2+}\right.$-activated $\mathrm{K}^{+}$-channel blocker, $5 \mathrm{mM}$ ), apamin (a small conductance $\mathrm{Ca}^{2+}$-activated $\mathrm{K}^{+}$channel blocker; APA, $10 \mathrm{nM}$ ) plus charybdotoxin (a middle and large conductance $\mathrm{Ca}^{2+}$-activated $\mathrm{K}^{+}$channel blocker; ChTX, $10 \mathrm{nM}$ ) or $18 \alpha$-glycyrrhetinic acid (gap-junction inhibitor; $18 \alpha-\mathrm{GA}, 10 \mu \mathrm{M}$ ), and methoxamine at $2-7 \mu \mathrm{M}$ were examined in preparations with intact endothelium.

In another series of experiments, the vasodilator response to a bolus injection of acetylcholine or A23187 was examined in preparations with or without the endothelium. After equilibration, the preparation was perfused with Krebs' solution containing methoxamine ( 2 to $7 \mu \mathrm{M}$ ) or methoxamine plus one of various inhibitors (L-NAME, indomethacin, tetraethylammonium, APA plus ChTX, high KCL, or $18 \alpha-\mathrm{GA}$ ) to induce submaximal contraction. After stabilization of the elevated perfusion pressure, acetylcholine $(1 \mathrm{nmol})$ and A23187 $(10 \mu \mathrm{mol})$ diluted with Krebs solution containing methoxamine and various inhibitors were infused directly into the perfusate proximal to the arterial cannula with an infusion pump.

At the end of each experiment, $100 \mu \mathrm{M}$ papaverine was perfused to produce complete relaxation. In experiments using acetylcholine and A23187, vasodilator activity was expressed as a percent of the perfusion pressure at maximum relaxation induced by papaverine. The maximum increase in perfusion pressure induced by methoxamine and high $\mathrm{KCl}$ was taken as the maximum vasoconstrictor response and $100 \%$, which was set as time 0 , and the time-dependent changes in perfusion pressure were observed for $180 \mathrm{~min}$ and expressed as a percent of the maximum vasoconstriction (peak amplitude). Changes in the peak amplitude at 60,120 and $180 \mathrm{~min}$ were also expressed as percent change of maximum vasoconstriction.

\section{Statistical analysis}

Data are each shown as the mean \pm S.E.M. Statistical analysis was performed by Student's $t$-test for unpaired observations between two groups and one-way analysis of variance followed by Tukey's test for multiple comparisons. $P<0.05$ was considered statistically significant.

\section{Drugs}

The following drugs were used in this study: A23187 (5-methylamino-2-[[(2S,3R,5R,6S,8R,9R)-3,5,9trimethyl-2-[(2S)-1-oxo-1-(1H-pyrrol-2-yl)propan-2-yl]1,7-dioxaspiro[5.5] undecan-8-yl]methyl] benzoxazole4-carboxylic acid) (Sigma Aldrich Japan, Tokyo), acetylcholine chloride (Daiichi-Sankyo Pharmaceutical Co., Tokyo), APA (Sigma Aldrich), 18 $\alpha$-GA (Wako Pure Chemical Ind., Ltd., Osaka), ChTX (Sigma Aldrich), indomethacin (Sigma Aldrich), methoxamine hydrochloride (Nihon Shinyaku, Kyoto), KCl (Wako), LNAME (Sigma Aldrich), papaverine hydrochloride (Dainippon-Sumitomo Pharmaceutical Co., Osaka), sodium deoxycholate (Ishizu Seiyaku Co., Tokyo), and tetraethylammonium (Sigma Aldrich). 18 $\alpha$-GA was dissolved in dimethylsulfoxide, and sodium deoxycholate was dissolved in $0.9 \%$ saline. All other drugs were dissolved in distilled water and diluted with Krebs solution containing $1-10 \mu \mathrm{M}$ methoxamine when perfused or injected directly.

\section{Results}

Vasoconstrictor responses to continuous perfusion of methoxamine and high $\mathrm{KCl}$

As shown in Fig. 1, in the preparations with intact endothelium, continuous perfusion of methoxamine at concentrations of 3,7 , and $10 \mu \mathrm{M}$ induced an initial sharp increase in perfusion pressure (phasic constriction) followed by a continuous increase in perfusion pressure (tonic constriction) in a concentration-dependent manner. However, the amplitude of sustained contraction induced by methoxamine was gradually reduced during 180-min perfusion in a time-dependent manner. As shown in Fig. 2A, the initial maximum vasoconstriction in responses to methoxamine at concentrations of 3,7 , and $10 \mu \mathrm{M}$ were decreased to $50 \%, 20 \%$, and $60 \%$ of the initial level at $180 \mathrm{~min}$, respectively. The time-dependent reduction of contractile response to methoxamine perfusion at a concentration of $7 \mu \mathrm{M}$ was greater than those to 
A

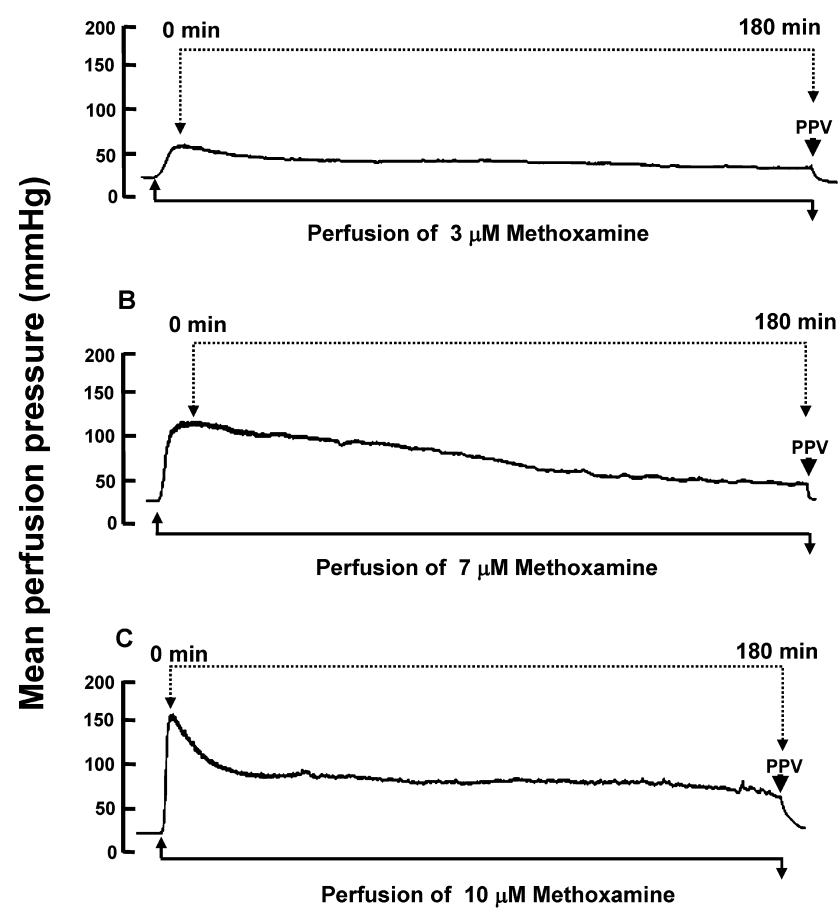

Fig. 1. Typical records showing changes in perfusion pressure following perfusion of methoxamine at concentrations of 3 (A), 7 (B), and 10 (C) $\mu \mathrm{M}$ for $180 \mathrm{~min}$ in rat-perfused mesenteric vascular beds with intact endothelium. Time 0 indicates the maximum increase in perfusion pressure after starting continuous perfusion of methoxamine. PPV, perfusion of $100 \mu \mathrm{M}$ papaverine.

other concentrations (Fig. 2B).

Perfusion of Krebs solution with high $\mathrm{KCl}(30,60$, and $80 \mathrm{mM}$ ) induced vasoconstriction in a concentrationdependent manner (Fig. 3). However, initial levels of increased perfusion pressure induced by perfusion of high $\mathrm{KCl}$ at concentrations of 30,60 , and $80 \mathrm{mM}$, which produced perfusion pressure increases similar to methoxamine at 3,7 , and $10 \mu \mathrm{M}$ (Table 1), respectively, were maintained over 180 min throughout the experiment and no time-dependent reduction was observed (Figs. 3 and 4).

Effects of endothelium removal on vasoconstriction induced by methoxamine and high $\mathrm{KCl}$

Vasoconstriction induced by methoxamine, but not high $\mathrm{KCl}$, was augmented by chemical removal of the vascular endothelium. Therefore, to obtain a perfusion pressure increase similar to that induced by $7 \mu \mathrm{M}$ methoxamine in the preparation with endothelium, the concentration of methoxamine was reduced to $2 \mu \mathrm{M}$ in the preparation without endothelium. In this preparation, the time-dependent reduction of methoxamine-induced vasoconstriction was significantly attenuated as shown in Fig. 5, A, C, and D. However, no significant change in

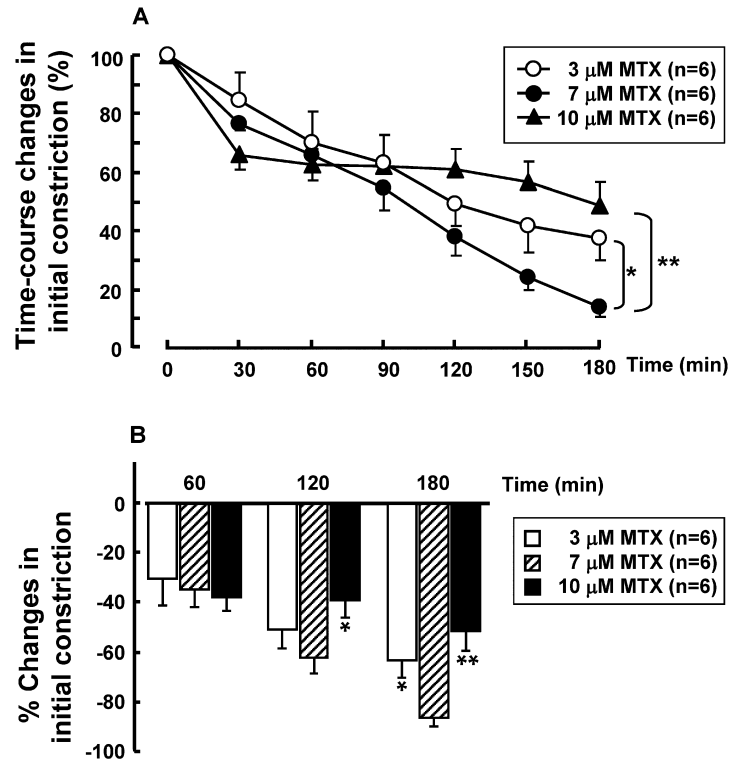

Fig. 2. A line graph (A) showing time-course changes (\%) in maximum increase in perfusion pressure induced by continuous perfusion of 3, 7, and $10 \mu \mathrm{M}$ methoxamine for $180 \mathrm{~min}$ and a bar graph (B) showing percent changes in methoxamine-induced maximum perfusion pressure increase at 60,120 , and $180 \mathrm{~min}$ in rat perfused mesenteric vascular beds with intact endothelium. Time 0 indicates the maximum increase in perfusion pressure after starting continuous perfusion of methoxamine and was taken as $100 \%$. MTX, methoxamine. Data each indicate the mean \pm S.E.M. ${ }^{*} P<0.05$, $* * P<0.01$, compared with $7 \mu \mathrm{M}$ MTX.

vasoconstrictor responses induced by high $\mathrm{KCl}(60 \mathrm{mM})$ was observed after endothelium removal (Fig. 5: B, C, and D).

Effects of L-NAME and indomethacin on vasoconstriction induced by methoxamine

In preparations with intact endothelium, combined perfusion of $100 \mu \mathrm{M}$ L-NAME, but not indomethacin, augmented the methoxamine-induced vasoconstriction as observed in endothelium removal. Therefore, the concentration of methoxamine in combination with LNAME was reduced to $2 \mu \mathrm{M}$, which induced a perfusion pressure increase similar to that induced by $7 \mu \mathrm{M}$ methoxamine without L-NAME. As shown in Fig. 6, neither L-NAME nor indomethacin had a significant effect on the time-dependent reduction of methoxamineinduced vasoconstriction.

Effects of $\mathrm{K}^{+}$-channel inhibitors and a gap-junction inhibitor on vasoconstriction induced by methoxamine

As shown in Fig. 7A, in preparations with intact endothelium, combined perfusion of high $\mathrm{KCl}(30 \mathrm{mM})$, $5 \mathrm{mM}$ tetraethylammonium or $10 \mathrm{nM}$ APA plus $10 \mathrm{nM}$ ChTX and methoxamine $(7 \mu \mathrm{M})$ significantly inhibited 


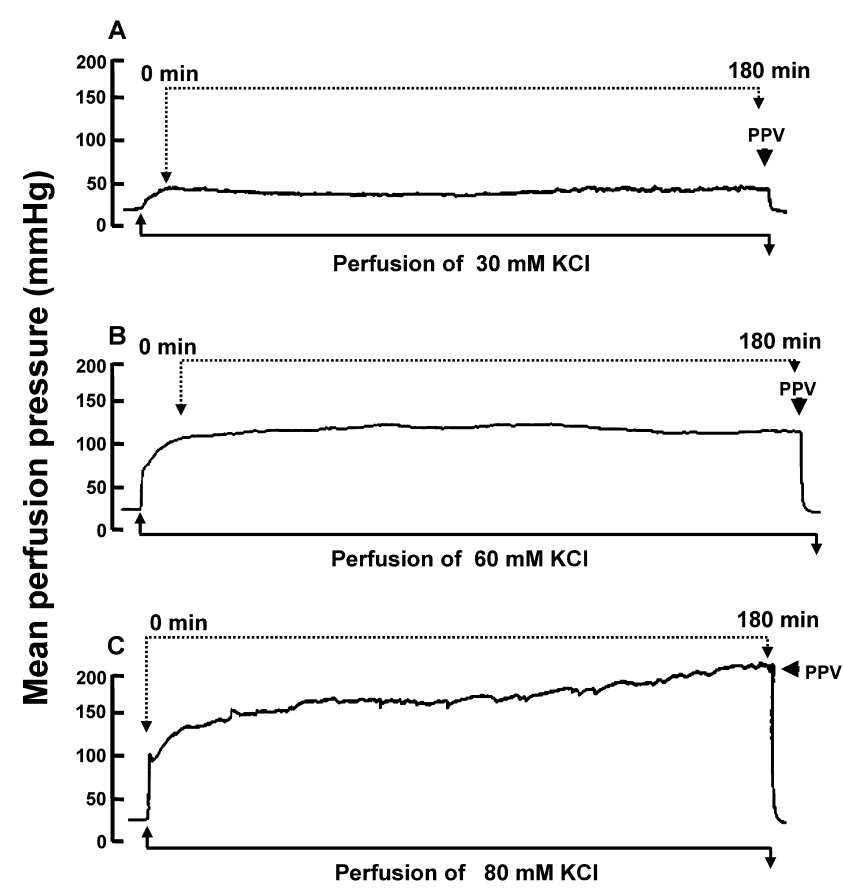

Fig. 3. Typical records showing changes in perfusion pressure following perfusion of Krebs solution containing high $\mathrm{KCl}$ at 30 (A), 60 (B), and 80 (C) $\mathrm{mM} \mathrm{KCl}$ for $180 \mathrm{~min}$ in rat-perfused mesenteric vascular beds with intact endothelium. Time 0 indicates the maximum increase in perfusion pressure after starting continuous perfusion of high $\mathrm{KCl}$. PPV, perfusion of $100 \mu \mathrm{M}$ papaverine.

the time-dependent reduction of methoxamine-induced vasoconstriction. In the presence of high $\mathrm{KCl}$ or tetraethylammonium, the initial vasoconstriction (phasic phase) induced by methoxamine was sustained over $180 \mathrm{~min}$, while a small time-dependent reduction in vasoconstriction was observed in combination with APA and ChTX (Fig. 7C).

As shown Fig. 7B, 18 $\alpha$-GA, a gap-junction inhibitor,
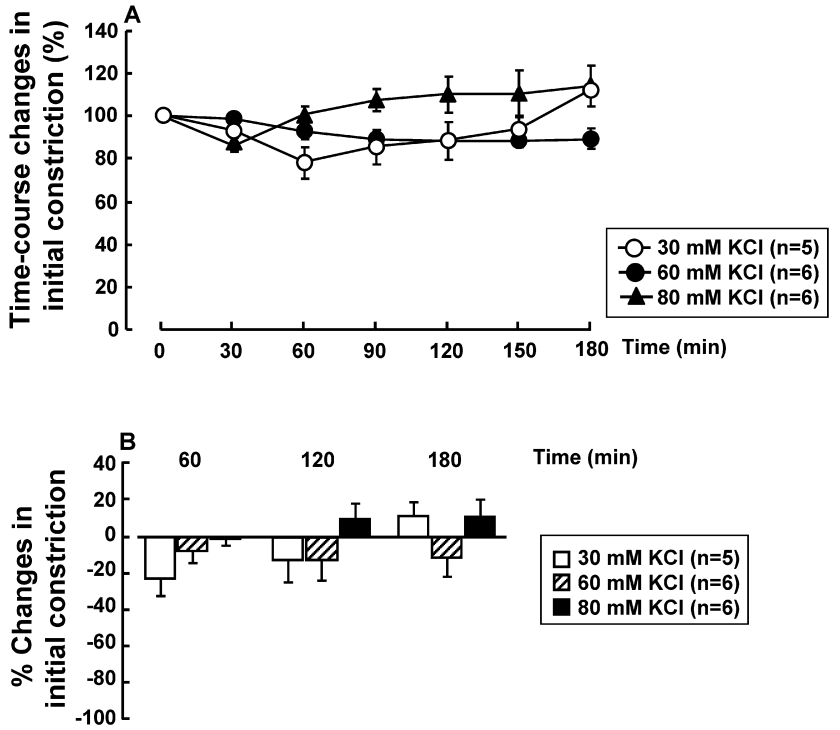

Fig. 4. A line graph (A) showing time-course changes (\%) in maximum increase in perfusion pressure induced by continuous perfusion of Krebs solution containing high $\mathrm{KCl}$ at 30,60 , and $80 \mathrm{mM} \mathrm{KCl}$ for $180 \mathrm{~min}$ and a bar graph (B) showing percent changes of high $\mathrm{KCl}$-induced perfusion pressure increase at 60,120 , and $180 \mathrm{~min}$ in rat-perfused mesenteric vascular beds with intact endothelium. Time 0 indicates the maximum increase in perfusion pressure after starting continuous perfusion of high $\mathrm{KCl}$ and was taken as $100 \%$. Data each indicate the mean \pm S.E.M.

significantly inhibited the time-dependent reduction of methoxamine-induced vasoconstriction.

Vasodilator responses to acetylcholine and A23187

In preparations with intact endothelium and active tone, bolus injection of acetylcholine $(1 \mathrm{nmol})$ or A23187 $(10 \mu \mathrm{mol})$ produced a sharp and transient decrease in perfusion pressure due to vasodilation. As

Table 1. The perfusion pressure at resting tension, maximum increase in perfusion pressure with perfusion of methoxamine and high $\mathrm{KCl}$, and perfusion pressure after perfusion of papaverine (PPV)

\begin{tabular}{lccc}
\hline & $\begin{array}{c}\text { Resting tension } \\
(\mathrm{mmHg})\end{array}$ & $\begin{array}{c}\text { Maximum increase } \\
\text { in perfusion pressure } \\
(\mathrm{mmHg})\end{array}$ & $\begin{array}{c}\text { After PPV perfusion } \\
(\mathrm{mmHg})\end{array}$ \\
\hline Methoxamine & & & \\
$3 \mu \mathrm{M}(\mathrm{n}=6)$ & $27.1 \pm 2.0$ & $58.6 \pm 5.1^{* *}$ & $27.9 \pm 1.8$ \\
$7 \mu \mathrm{M}(\mathrm{n}=6)$ & $28.5 \pm 2.0$ & $114.2 \pm 4.5^{* *}$ & $31.8 \pm 1.8$ \\
$10 \mu \mathrm{M}(\mathrm{n}=6)$ & $31.3 \pm 1.6$ & $149.1 \pm 9.5^{* *}$ & $34.9 \pm 1.2$ \\
\hline $\mathrm{KCl}$ & & & \\
$30 \mathrm{mM}(\mathrm{n}=5)$ & $29.4 \pm 1.5$ & $47.7 \pm 5.4^{* *}$ & $31.5 \pm 2.4$ \\
$60 \mathrm{mM}(\mathrm{n}=6)$ & $31.1 \pm 0.9$ & $117.8 \pm 7.2^{* *}$ & $33.9 \pm 2.4$ \\
$80 \mathrm{mM}(\mathrm{n}=6)$ & $28.6 \pm 0.7$ & $142.2 \pm 4.3^{* *}$ & $31.9 \pm 1.1$ \\
\hline
\end{tabular}

Data each indicate the mean \pm S.E.M. ${ }^{* *} P<0.01$, compared with resting tone. $n$, number of rats. 

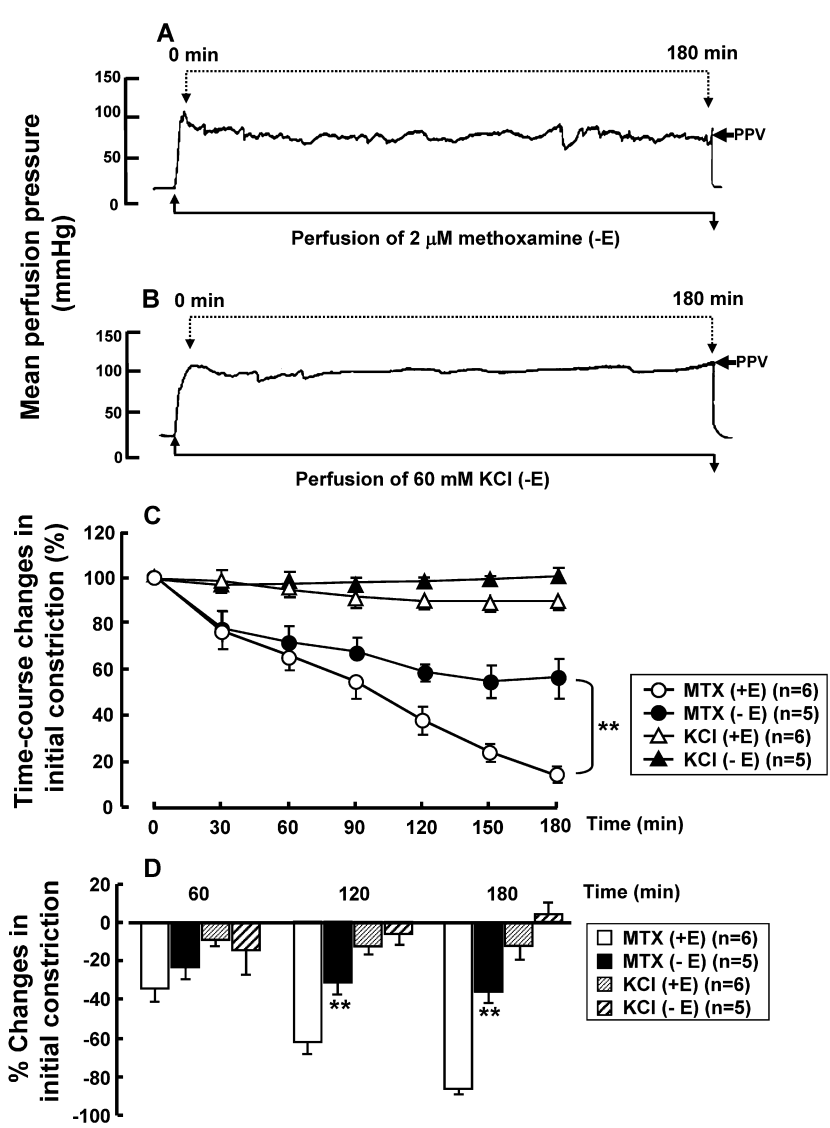

Fig. 5. Effect of endothelium removal on vasoconstrictor responses to continuous perfusion of $2 \mu \mathrm{M}$ methoxamine and high $\mathrm{KCl}(60 \mathrm{mM})$ for $180 \mathrm{~min}$ in rat perfused mesenteric vascular beds. Upper charts are typical records of methoxamine (A) and high $\mathrm{KCl}(\mathrm{B})$. A line graph (C) and a bar graph (D) show time-course changes in maximum increase in perfusion pressure induced by $2 \mu \mathrm{M}$ methoxamine and high $\mathrm{KCl}(60 \mathrm{mM})$ and percent changes in methoxamine- and high$\mathrm{KCl}-$ induced maximum perfusion pressure increase at 60,120 , and $180 \mathrm{~min}$, respectively. Time 0 indicates the maximum increase in perfusion pressure after starting continuous perfusion of methoxamine and high $\mathrm{KCl}$ and was taken as $100 \%$. MTX, methoxamine; PPV, perfusion of $100 \mu \mathrm{M}$ papaverine; (+E), with intact endothelium; (-E), endothelium removal. Data each indicate the mean \pm S.E.M. ** $P<0.01$, compared with methoxamine $(+\mathrm{E})$.

shown in Table 2, the relaxations induced by both acetylcholine and A23187 were almost abolished by removal of the endothelium, and significantly inhibited by high $\mathrm{KCl}(30 \mathrm{mM})$ and tetraethylammonium $(5 \mathrm{mM})$, while L-NAME $(100 \mu \mathrm{M})$ or L-NAME $(100 \mu \mathrm{M})$ plus indomethacin $(1 \mu \mathrm{M})$ had no effect on the acetylcholineand A23187-induced vasodilation. Furthermore, $18 \alpha-\mathrm{GA}$ $(10 \mu \mathrm{M})$ alone had no significant effect on the acetylcholine- and A23187-induced vasodilation. However, the combined presence of L-NAME $(100 \mu \mathrm{M})$ and $18 \alpha-$ GA $(10 \mu \mathrm{M})$ significantly inhibited the vasodilation induced by A23187, but not acetylcholine.
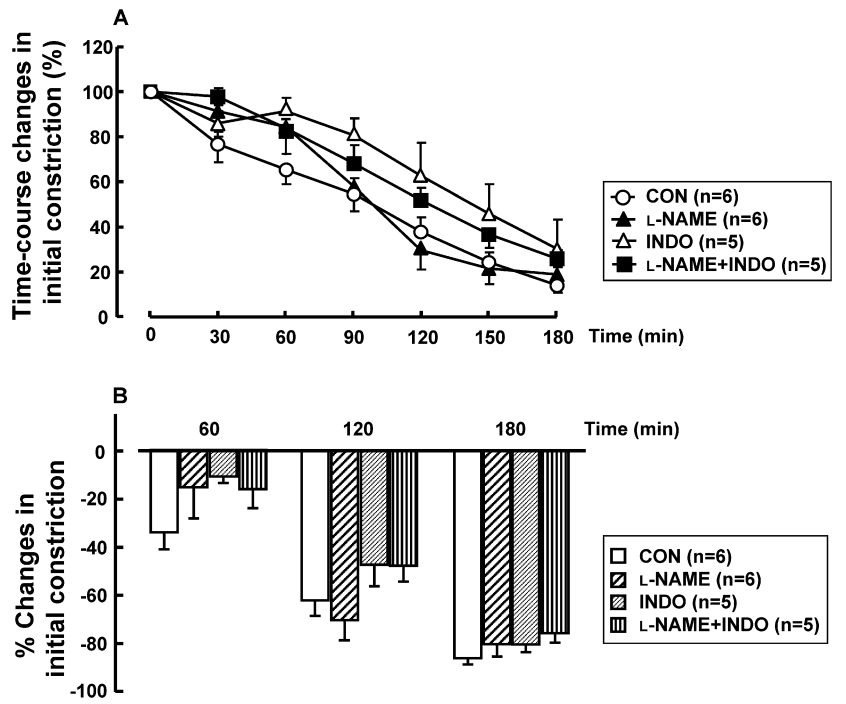

Fig. 6. A line graph (A) showing the effects of $N^{\mathrm{G}}$-nitro-L-argininemethyl ester (L-NAME, $100 \mu \mathrm{M}$ ) and indomethacin (INDO, $1 \mu \mathrm{M}$ ) on time-course changes (\%) in maximum increase in perfusion pressure induced by continuous perfusion of methoxamine $(7 \mu \mathrm{M})$ and a bar graph (B) showing percent changes in methoxamine-induced maximum perfusion pressure increase at 60,120 , and $180 \mathrm{~min}$ in rat perfused mesenteric vascular beds with intact endothelium. Time 0 indicates the maximum increase in perfusion pressure after starting continuous perfusion of methoxamine and was taken as $100 \%$. Data each indicate the mean \pm S.E.M. CON, control.

\section{Discussion}

The present study demonstrated that, in the rat mesenteric artery with intact endothelium, continuous perfusion of an $\alpha_{1}$-adrenoceptor agonist, methoxamine, concentration-dependently caused a long-lasting increase in perfusion pressure due to vasoconstriction, which consisted of an initial fast constriction (phasic phase) followed by sustained constriction (tonic phase). However, the tonic phase of methoxamine-induced vasoconstriction gradually decreased during 180-min perfusion, causing $80 \%$ reduction in the initial level at $180 \mathrm{~min}$, indicating that the tonic phase is timedependent. In contrast, continuous perfusion of Krebs solution with high $\mathrm{KCl}$ induced a $\mathrm{K}^{+}$-concentrationdependent increase in perfusion pressure that was sustained over 180-min perfusion without reduction. This finding suggests that the contractile ability of smooth muscle cells in the rat mesenteric artery is maintained over a 180 -min perfusion. It is unlikely that the time-dependent reduction of methoxamine-induced vasoconstriction is due to decreased constrictive activity of arterial smooth muscles. Furthermore, since high $\mathrm{KCl}$ blunts $\mathrm{K}^{+}$-channels activity, $\mathrm{K}^{+}$-channels are likely to be involved in the time-dependent reduction of methoxamine-induced vasoconstriction. 

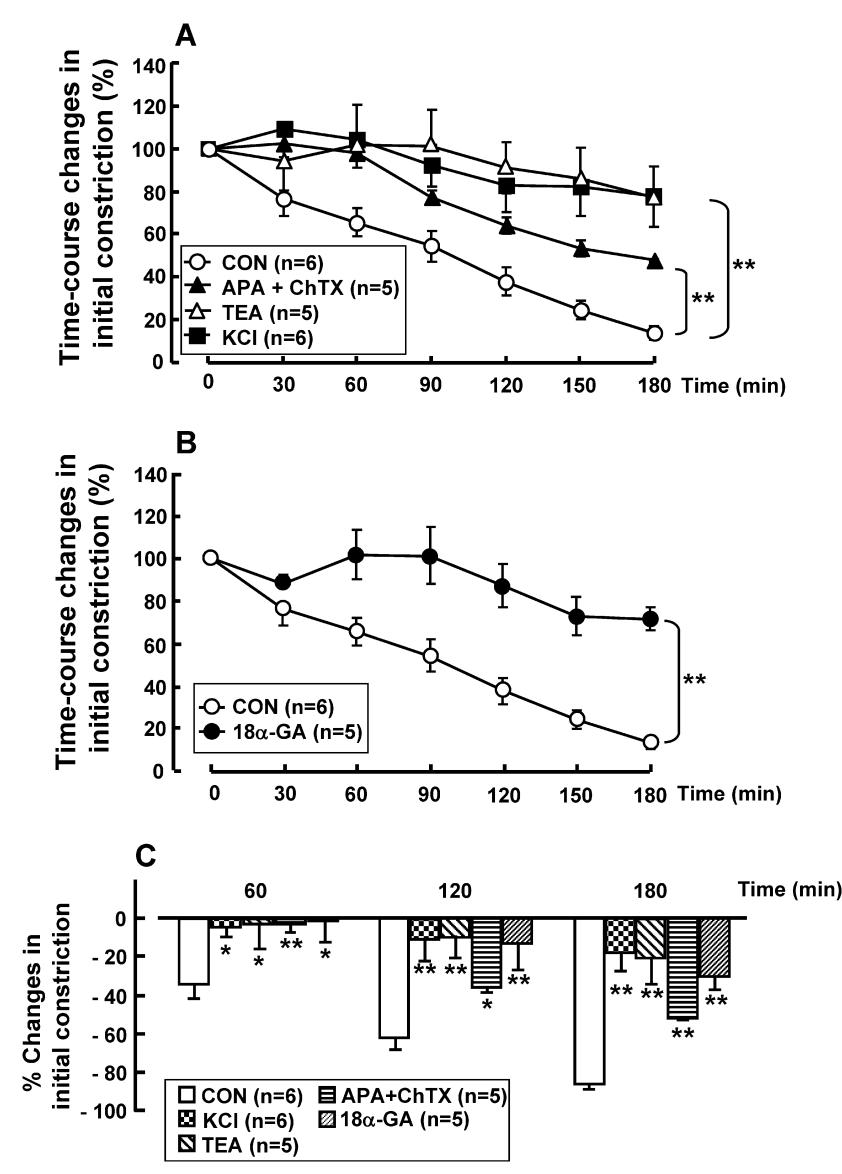

In the present study, removal of the endothelium augmented the phasic phase of the methoxamineinduced vasoconstriction and markedly attenuated the time-dependent reduction of tonic phase constriction. This finding strongly suggests that the endothelium plays an important inhibitory role in vasoconstriction
Fig. 7. Line graphs showing the effects of high $\mathrm{KCl}(30 \mathrm{mM})(\mathrm{A})$, tetraethylammonium (TEA, $5 \mathrm{mM})(\mathrm{A}), 10 \mathrm{nM}$ apamin plus $10 \mathrm{nM}$ charybdotoxin (APA + ChTX) (A), and 18 $\alpha$-glycyrrhetinic acid $(18 \alpha-$ $\mathrm{GA}, 10 \mu \mathrm{M})(\mathrm{B})$ on time-course changes (\%) in maximum increase in perfusion pressure induced by continuous perfusion of methoxamine $(7 \mu \mathrm{M})$. A bar graph (C) showing the effects of $\mathrm{KCl}$, TEA, $\mathrm{APA}+\mathrm{ChTX}$, and $18 \alpha$-GA on percent changes in methoxamineinduced maximum perfusion pressure increase at 60,120 , and $180 \mathrm{~min}$ in rat perfused mesenteric vascular beds with intact endothelium. Time 0 indicates the maximum increase in perfusion pressure after starting continuous perfusion of methoxamine and was taken as $100 \%$. Data each indicate the mean \pm S.E.M. ${ }^{*} P<0.05$, $* * P<0.01$, compared with control $(\mathrm{CON})$.

induced by methoxamine. Furthermore, indomethacin, a prostanoid synthase cyclooxygenase inhibitor, did not alter the phasic or tonic constriction in response to methoxamine, while NO synthase inhibition by LNAME augmented the methoxamine-induced phasic constriction to a similar extent to that of endothelium removal, but it did not alter the time-dependent reduction of tonic phase constriction. Thus, it is suggested that NO released from the endothelium is responsible for suppression of methoxamine-induced phasic constriction. It is very likely that non-NO and non-prostacyclin factors released from the endothelium are involved in time-dependent reduction of tonic phase constriction.

Methoxamine selectively stimulates $\alpha_{1}$-adrenoceptors to induce direct constriction of vascular smooth muscle in rat mesenteric arteries. However, methoxamine has been shown to have no direct action on the endothelial cells (21), implying that it does not directly stimulate endothelial cells to release EDRF. The most likely explanation is that methoxamine-induced vasoconstriction in isolated mesenteric resistance arteries results in

Table 2. Effects of various treatments on vasodilation induced by acetylcholine (ACh) and $\mathrm{Ca}^{2+}$ ionophore A23187 (A23187) in rat perfused mesenteric vascular beds with active tone

\begin{tabular}{lcc}
\hline \multirow{2}{*}{ Treatments } & \multicolumn{2}{c}{ Vasodilation (\%) } \\
\cline { 2 - 3 } & $1 \mathrm{nmol}$ ACh $(\mathrm{n})$ & $10 \mu \mathrm{mol}$ A23187 (n) \\
\hline Control & $81.7 \pm 3.1(6)$ & $71.7 \pm 4.0(6)$ \\
Endothelium removal & $9.4 \pm 2.1^{* *}(6)$ & $11.8 \pm 5.9^{* *}(5)$ \\
L-NAME $(100 \mu \mathrm{M})$ & $71.3 \pm 1.9(6)$ & $68.7 \pm 4.2(6)$ \\
L-NAME $(100 \mu \mathrm{M})+$ INDO $(1 \mu \mathrm{M})$ & $75.2 \pm 2.2(5)$ & $68.0 \pm 5.4(5)$ \\
High KCl $(30 \mathrm{mM})$ & $24.7 \pm 1.4^{* *}(6)$ & $21.5 \pm 6.5^{* *}(5)$ \\
Tetraethylammonium $(5 \mathrm{mM})$ & $49.3 \pm 8.9^{*}(5)$ & $56.2 \pm 6.9^{*}(5)$ \\
$18 \alpha-G A(10 \mu \mathrm{M})$ & $82.4 \pm 6.6(5)$ & $76.2 \pm 2.0(5)$ \\
L-NAME $(100 \mu \mathrm{M})+18 \alpha-\mathrm{GA}(10 \mu \mathrm{M})$ & $70.7 \pm 4.0(5)$ & $41.3 \pm 8.0^{* \dagger}(5)$ \\
\hline
\end{tabular}

Data each indicate the mean \pm S.E.M. (n), number of rats. L-NAME, $N^{\mathrm{G}}$-L-nitro arginine methyl ether; INDO, indomethacin; $18 \alpha$-GA, $18 \alpha$-glycyrrhetinic acid. $* P<0.05, * * P<0.01$, compared with the control. ${ }^{\dagger} P<0.05$, compared with L-NAME alone. 
increased endothelial mechanical stimuli, which stimulate the endothelium and elicit the release of EDRF.

It should be noted that the time-dependent reduction of methoxamine (3, 7, and $10 \mu \mathrm{M})$-induced tonic constriction was not concentration-dependent, and reduction of vasoconstriction induced by the concentration of $7 \mu \mathrm{M}$ (middle) was greater than that induced by the other two concentrations (low and high). The explanation for this phenomenon is that vasoconstriction induced by a low concentration is an insufficient stimulus to promote the EDRF release process, while the endothelium is unable to overwhelm higher concentration-induced vasoconstriction. This notion is supported by the report by Gündüz et al. (22) that high intravascular pressure impairs both endothelium-dependent and independent dilation of rat small mesenteric arteries.

EDHF, which has been described as an endotheliumderived non-NO and non-PGI ${ }_{2}$ factor, induces hyperpolarization of vascular smooth muscle by opening $\mathrm{K}^{+}$ channels. Furthermore, several studies showed evidence that gap junctions also play an important role in EDHFmediated relaxation $(16,23,24)$. In the present study, the time-dependent reduction of methoxamine-induced vasoconstriction was abolished by nonselective $\mathrm{K}^{+}$channel blockade by $30 \mathrm{mM}$ high $\mathrm{KCl}$ medium and significantly inhibited by $\mathrm{K}^{+}$-channel blockers, including tetraethylammonium and APA plus ChTX; this combination of APA and ChTX has been reported to attenuate the action of $\operatorname{EDHF}(25,26)$. Furthermore, the inhibition of gap junctions by $18 \alpha$-GA resulted in marked inhibition of time-dependent reduction of methoxamineinduced vasoconstriction. It has been reported that $18 \alpha-$ GA inhibits endothelium-dependent EDHF-type relaxation mediated via myo-endothelial gap junctions (27, 28). Therefore, it seems likely that myo-endothelial gap junctions are mainly responsible for the time-dependent reduction, but involvement of inter-endothelial and inter-smooth muscle junctions may also be possible. Taken together, these findings suggest that the endothelium acts to depress methoxamine-induced tonic phase vasoconstriction by the EDHF-mediated response, which is associated with activation of multiple $\mathrm{K}^{+}$channels and myo-endothelium gap-junction involvement in mesenteric resistance arteries. Several studies suggested that NO and EDHF have an interdependent action on endothelium function. Therefore, it is assumed that in the present study the endothelium released NO to suppress the initial phase of vasoconstriction, followed by the EDHF-mediated response to compensate for the insufficient inhibitory effect of NO, resulting in a timedependent reduction of tonic phase vasoconstriction.

Acetylcholine evokes endothelium-dependent relaxation through activation of muscarinic acetylcholine receptors, which increase the $\mathrm{Ca}^{2+}$ levels of endothelial cells from intracellular stores and $\mathrm{Ca}^{2+}$-influx. However, A23187 increases $\mathrm{Ca}^{2+}$ concentrations by directly increasing intracellular $\mathrm{Ca}^{2+}$-levels from internal stores without stimulating any receptors. Here, we demonstrated that both acetylcholine- and A23187-induced vasodilation were significantly attenuated by endothelium removal, tetraethylammonium, and high $\mathrm{KCl}$ and slightly inhibited by $18 \alpha-\mathrm{GA}$, but neither were affected by L-NAME or indomethacin, suggesting that the responses to both A23187 and acetylcholine are endothelium-dependent and mainly mediated by nonNO and non-prostanoid EDHF. Furthermore, the response to A23187, but not acetylcholine, was significantly inhibited by the combined presence of $18 \alpha-\mathrm{GA}$ and L-NAME. These findings suggest that gap junctions are responsible for A23187-induced EDHF-mediated response as involved in the time-dependent reduction of methoxamine-induced vasoconstriction, whereas gap junctions do not contribute to the acetylcholine-induced EDHF-mediated response. Therefore, it is possible that the endothelium releases different types of EDHF to regulate vascular tone in response to various stimuli in mesenteric resistance arteries.

In conclusion, the present results suggest that the endothelium in mesenteric resistance arteries acts to depress methoxamine-induced tonic phase vasoconstriction by the EDHF-mediated response, which is associated with activation of multiple $\mathrm{K}^{+}$-channels and gap-junction involvement.

\section{References}

1 Mulvany MJ, Aalkjaer C. Structure and function of small arteries. Physiol Rev. 1990;70:921-961.

2 Furchgott RF, Zawadzki JV. The obligatory role of endothelial cells in the relaxation of arterial smooth muscle by acetylcholine. Nature. 1980;288:373-376.

3 Ress SR, Ratanjee B, Meyers OL, Keraan M. Laboratory assessment of immune status: uses and limitations. Br J Clin Pract. 1986;40:288-291.

4 Moncada S, Palmer RM, Higgs EA. Nitric oxide: physiology, pathophysiology, and pharmacology. Pharmacol Rev. 1991;43: 109-142.

5 Garland CJ, Plane F, Kemp BK, Cocks TM. Endotheliumdependent hyperpolarization: a role in the control of vascular tone. Trends Pharmacol Sci. 1995;16:23-30.

6 Vanhoutte PM, Mombouli JV. Vascular endothelium: Vasoactive mediators. Prog Cardiovasc Dis. 1996;39:229-238.

7 Martin W, Furchgott RF, Villani GM, Jothianandan D. Depression of contractile responses in rat aorta by spontaneously released endothelium-derived relaxing factor. J Pharmacol Exp Ther. 1986;237:529-538.

8 Yamaguchi T, Rodman D, O’Brien R, McMurtry I. Modulation of pulmonary artery contraction by endothelium-derived relaxing factor. Eur J Pharmacol. 1989;161:259-262. 
9 Segarra G, Medina P, Revert F, Masiá S, Vila JM, Such L, et al. Modulation of adrenergic contraction of dog pulmonary arteries by nitric oxide and prostacyclin. General Pharmacol. 1999; 32:583-589.

10 Iwatani $\mathrm{Y}$, Kosugi $\mathrm{K}$, Isobe-Oku S, Atagi S, Kitamura Y, Kawasaki H. Endothelium removal augments endotheliumindependent vasodilatation in rat mesenteric vascular bed. $\mathrm{Br} \mathrm{J}$ Pharmacol. 2008;154:32-40.

11 Shimokawa H, Yasutake H, Fujii K, Owada MK, Nakaike R, Fukumoto Y, et al. The importance of the hyperpolarizing mechanism increases as the vessel size decreases in endotheliumdependent relaxations in rat mesenteric circulation. J Cardiovasc Pharmacol. 1996;28:703-711.

12 Scotland RS, Chauhan S, Vallance PJ, Ahluwalia A. An endothelium-derived hyperpolarizing factor-like factor moderates myogenic constriction of mesenteric resistance arteries in the absence of endothelial nitric oxide synthase-derived nitric oxide. Hypertension. 2001;38:833-839.

13 Zhou MS, Raij L. Cross-talk between nitric oxide and endothelium-derived hyperpolarizing factor: synergistic interaction? J Hypertens. 2003;21:1449-1451.

14 Chen G, Suzuki H, Weston AH. Acetylcholine releases endothelium-derived hyperpolarizing factor and EDRF from rat blood vessels. Br J Pharmacol. 1988;95:1165-1174.

15 Edwards G, Dora KA, Gardener MJ, Garland CJ, Weston AH. $\mathrm{K}^{+}$is an endothelium-derived hyperpolarizing factor in rat arteries. Nature. 1998;396:269-272.

16 Edwards G, Félétou M, Gardener MJ, Thollon C, Vanhoutte PM, Weston AH. Role of gap junctions in the responses to EDHF in rat and guinea-pig small arteries. Br J Pharmacol. 1999;128: 1788-1794.

17 Kawasaki H, Takasaki K, Saito A, Goto K. Calcitonin generelated peptide acts as a novel vasodilator neurotransmitter in mesenteric resistance vessels of the rat. Nature. 1988;335:164 167.

18 Kawasaki H, Nuki C, Saito A, Takasaki K. Role of calcitonin gene-related peptide-containing nerves in the vascular adrenergic neurotransmission. J Pharmacol Exp Ther. 1990;252:403-409.
19 Takenaga M, Kawasaki H. Endogenous calcitonin gene-related peptide suppresses vasoconstriction mediated by adrenergic nerves in rat mesenteric resistance blood vessels. Eur J Pharmacol. 1999;367:239-245.

20 Shiraki H, Kawasaki H, Tezuka S, Nakatsuma A, Kurosaki Y. Endogenous calcitonin gene-related peptide (CGRP) mediates adrenergic-dependent vasodilation induced by nicotine in mesenteric resistance arteries of the rat. $\mathrm{Br} \mathrm{J}$ Pharmacol. 2000;130:1083-1091.

21 Dora KA, Hinton JM, Walker SD, Garland CJ. An indirect influence of phenylephrine on the release of endotheliumderived vasodilators in rat small mesenteric artery. $\mathrm{Br} \mathrm{J}$ Pharmacol. 2000;129:381-387.

22 Gündüz F, Meiselman HJ, Baskurt OK. High intravascular pressure attenuates vascular dilation responses of small mesenteric arteries in the rat. Circ J. 2008;72:482-486.

23 Yamamoto Y, Imaeda K, Suzuki H. Endothelium-dependent hyperpolarization and intercellular electrical coupling in guineapig mesenteric arterioles. J Physiol. 1999;514:505-513.

24 Sandow SL, Tare M, Coleman HA, Hill CE, Parkington HC. Involvement of myoendothelial gap junctions in the actions of endothelium-derived hyperpolarizing factor. Circ Res. 2002;90: 1108-1113.

25 Chen G, Cheung DW. Effect of $\mathrm{K}^{+}$-channel blockers on AChinduced hyperpolarization and relaxation in mesenteric arteries. Am J Physiol. 1997;272:2306-2312.

26 Petersson J, Zygmunt PM, Högestätt ED. Characterization of the potassium channels involved in EDHF-mediated relaxation in cerebral arteries. Br J Pharmacol. 1997;120:1344-1350.

27 Chaytor AT, Marsh WL, Hutcheson IR, Griffith TM. Comparison of glycyrrhetinic acid isoforms and carbenoxolone as inhibitors of EDHF-type relaxations mediated via gap junctions. Endothelium. 2000;7:265-278.

28 Taylor HJ, Chaytor AT, Evans WH, Griffith TM. Inhibition of the gap junctional component of endothelium-dependent relaxations in rabbit iliac artery by 18 -alpha glycyrrhetinic acid. Br J Pharmacol. 1998;125:1-3. 